\title{
Dr. İsmet Sözen'in (Türkiye Tıbbi Müstahzar Sanayi ve Laboratuvarları Derneği Başkanı) Konuşması
}

Fakülte'nizin 20 nci kuruluş yılını kutladığımız bu mutlu gününüzü candan kutlarım. Bumdan sonraki 20 senelerin de Türkiye'mize çok daha faydalı hizmetler vereceği inancı içindeyim.

$\mathrm{Bu}$ mutlu günümüzde ulusal ilaç sanayiini temsilen bana verilen bu konuşma imkânından dolayı Fakülte yöneticilerine teşekkürlerimi arz ederim.

İlaç sanayii, ruhumda eczacının olduğu, eczacısız düşünülemeyecek bir sanayidir. Ulusal ilaç sanayiimizin bugünkü seviyesine, meştrutiyetten önceki yıllara varan eczacılarımızın büyük gayretleri ile gelinmiştir.

İlaç sanayiinde iki cemiyet faaliyet göstermektedir. Bir tanesi benim başkanı olduğum Türkiye Tıbbi Müstahzarat Sanayi ve Laboratuvarları Cemiyeti olup, tamamen müh sermayeli ilaç firmalarını bünyesinde toplamaktadır ve 71 üyemiz vardır. Cemiyet 1951 senesinde kurulmuştur.

İlk kurucuları şunlardır;

Mustafa Nevzat PISAK, Cemil TUNA, Sami SİLE, Münir ŞAHİN, Hikmet GÜNEYMAN, Hasan SARPER, Nizamettin TABİB, İdris YAYBULAK.

Diğer kuruluş, Türkiye İlaç İş Verenleri Sendikası olup, yabancı sermayeli ilaç firmaları ile, bir kısım milli sermayeli ilaç firmalarım bünyesinde toplamaktadır.

Ulusal ilaç sanayiimizin bu günkü gelişiminde eczacımızın rolünü tarih sırası ile kısaca arzetmek isterim.

İlk müstahzarlar 1805-1900'de Eczacı Süreyya Bey (baba) tarafından Elixir Süreyya (Demir Bileşiği) ve Eczacı Ethem Pertev Bey Paris'te açılan bir sergide Pertev Şurubunu teşhir etmiş, aynı yıllarda Ethem Pertev Bey Çemberlitaş'ta Eczanesinin arkasında ilk küçük ilaç fabrikasımı kurmuştur. Burada, meşrutiyette, komprimeciliği ilk başlatmıştır. Balkan harbinde bu laboratuvar orduya çok büyük hizmetler ifa etmiştir. Meşrutiyet devrinde Abdi İbrahim, S. Ferit Eczacıbaşı, İbrahim Ethem Laboratuvarları ça- 
1ışmalar yapmışlardır. Meşrutiyet devrinin sonlarına doğru kaşeler çıkmıştır.

İlk kodeks : 1S44'de askerlik müesseseleri için basılmış, 1882' senesinde Fransız Kodeksi tercüme edilip basılmıştır.

1905 senesinde ithal edilen ilaçların gümrüklerce muayenesine dair bir talimatname neşredildi.

İlaçlar için ilk defa Meşrutiyet devrinde, Meclis-i umur-i Tıbbiye-i mülkiye ve Sihhiye-i umumiye reisliği'ne müracaatla müstahzar yapma müsaadesi alınması başlatıldı. Bu müsaade de meslek aranmazd1.

Cumhuriyet devrinde müstahzar ve ilaç imali ilerleyince 1928' de şimdiki 1282 sayılı İspençiyari ve Tıbbi Müstahzarat Kanunu kabul edilmiştir.

1955 senesinde ispençiyari ve tıbbi müstahzarlar imalathaneleri talimatnamesi hazırlanmış ve bu suretle tıbbi müstahzarat yapımı ruhsat'a ve imalat yerleri de belirli kriterlere bağlanmıştır.

1932 senesinde imal edilen müstahzarların kıymeti 68.000 liradır. 1949 senesine kadar 1.544 ruhsatname alınmıştır. Aynı tarihler arasında yabancılar 2.415 ruhsat almışlardır.

1954 senesinde kabul edilen 6224 sayılı Yabanc1 Sermayeyi Teşvik Kanunundan yararlanarak yabancı sermayeli ilaç firmaları yurdumuza gelmeye başlamışlardır. 1960 senesinden itibaren bir çok yerli sermayeli ulusal firmalarımız halka açılarak Anonim Şirketler haline gelmişlerdir. 60 'h senelerde yabanc1 sermayeli bu firmaların yerli firmalarımıza görgü ve teknoloji bakımından katk1ları büyük olmuştur.

1980 - 19T2 seneleri ulusal sanayiimizin çok geliştiği senelerdir. Ancak 1972 senesinden itibaren tatbik edilen keyfi fiyatlandirma ve ruhsatname vermede uygulanan yanlış usul ve keyfi davranış sanayiimizde yenilenme imkânlarını azaltırken 1977-78-79 senelerinin enflasyonist gidişi sermaye eksikliğine sebebiyet vermiş ve dolayısıyle yavaşlama devrine girmiştir. 1980 senesinden itibaren ulusal sanayiimiz yeniden toparlanmaya başlamıştır. Ancak ruhsat vermede izlenen tutum uzun vadede karşımıza sorun olarak çıkacaktır.

Üretim :

I.M.S. verilerine göre 1 Ekim 1980 - 30 Eylül 1981 tarihleri 
arasında 34 milyar civarında mamul ilaç satışı olmuştur. Bunun takriben \% 32.01'ini yani 11 milyarlık kısmım tamamen yabanc1 sermayeli ilaç firmaları \% 67.09'unu, 23 milyar lirasını milli sermayeli ilaç firmalarımız yapmışlardır. Bu durumda görüldüğü gibi Ulusal ilaç Sanayiimiz aşağıdaki üç unsuru gerçekleştirmiştir.

1. Türkiye'de imal edilen ve satılan ilaçlar kalite koşulları bakımından uluslararası standarda uygun üretilmektedir.

2. Kullanılan ilaçların tamamı yerli imal edümektedir. Ayrıca tamamına yakınını, milli ilaç sanayii yapabilecek kapasiteye ve imkânlara sahiptir.

3. Hangi kriterle karşılaştırılırsa karşılaştırılsın dünyada en ucuz fiyatlarla ilaç satmaktadır.

Hammadde Üretimi :

Türkiye'ye 140 milyon dolar civarında ham ve yardımcı madde ithal edilmektedir. Bunun içine hammadde imalatındaki ilk maddeler de girer. Türkiye'de üretilen ilaç hammaddesinin $\% 30^{\prime}$ unu milli ilaç sanayiine bağlı kuruluşlar, \% 5'ini yabancı sermayeli firmalara bağlı kuruluşlar üretmektedir.

Büyük çapta HAMMADDE imal eden Milli Kuruluşlar şunlardir :

Ansa ilaç Sanayi,

M. Nevzat İlaç Sanayii,

Atabay İlaç Sanayii,

Deva İlaç Sanayii,

Fako İlaç Sanayii,

Milen İlaç Sanayii.

Hammadde sanayii daha çok kimya sanayiini ilgilendiren bir branştır. Üretim teknolojisi, yatırım ve teçhizat gereksinmeleri ilaç imalâtından tamamen farklıdır. Ülkemizde alt yapı ve temel kimya endüstrisinin kurulması lazımdır. Esasen hiçbir ülke yoktur ki ilaç hammaddesinin tamamını yapabilsin. İlaç sanayiinde 2.400 civarında ham ve yardımcı madde çeşidi vardır. Hammadde imalatında çok eksiğimiz vardır. Yetişecek gençlerimize bu hususta çok iş düşmektedir. Benden sonraki konuşmacı arkadaşlarım bu mevzuda geniş bilgiler verecektir.

\section{Araştırma ve Geliştirme:}

Dünya'da ilaç araştırması için çok büyük miktarlarda paralar 
harcanmaktadır. Bu harcamalar ya çok uluslu şirketlerin merkezlerinde ya da devletlerce yapilmaktadir.

Ülkemizde bu hususta bir takım hareketler yapılmak istenmektedir, ancak yabancı sermayeli ilaç firmaları bu hususta merkezlerinde araştırma yaptığı için ayrıca ülkemizde araştırmaya lüzum görmemektedirler.

Milli ilaç sanayiimiz için durum değişiktir. Araştırmanın büyük paralar istediği aşikârdır. 1972 senesinde şimdiki fiyat kararnamesi hazırlanırken başkanlığını Sayın Mekin Tanker'in yaptığı bir komisyon kurulmuştu. $\mathrm{Bu}$ komisyon ilaç fiyatlandırması esnasında araştırma yapan veya yapacak firmalara ayrıca ilave fiyat vermeyi öngörmüştü. Ancak bugüne kadar böyle bir tatbikat yapılmamıştır. $\mathrm{Bu}$ da gösteriyor ki araştırma için ilave fonlara ihtiyaç vardır. Ulusal ilaç sanayiimiz araştırma zorunluğuna inanmaktadır. Ancak geçen 4-5 senenin enflasyonist gidişi sermayelerin eksilmesine sebep olmuştur. Bu sebeple geniş çaplı araştırmaya girmek zaman alacaktır.

İhracat :

Geçtiğimiz senelerde ancak yurt içi ihtiyacını karşılamaya çalışan firmalarımız bu sene içinde mamul ilaç ihracatını gerçekleştirmeye uğraşmaktadırlar. Yabancı sermayeli ilaç firmalarının gelişinde 6224 sayılı Kanunun ruhunda ihracat mecburiyeti olduğu halde onlarda bu yolda büyük gayret sarfetmemektedirler. Hammadde imalatçıları ihracat yapma imkânı bulmuşlardır, İlacın ihracı çok zorluklar arz eder. İhraç edilecek ülkede o ilaca ruhsat almak ve doktorlara, eczacılara tanıtmak çok yorucu ve maliyetlidir.

\section{Yurdumuzda İlaç Adedi :}

Ruhsatlı 7.000 civarında ilaç çeşidi vardır. Her ne kadar 20.000 civarında diye söylenmekte ise de, bu rakkam, yukarıda bildirdiğim 7.000 rakkamının miras yolu ile şirketleşmelerde veya el değiştirmelerde verilen defterdeki numaralardır.

Piyasada 2.500 - 3,000 civarında ilaç bulunmaktadır. Diğerleri ya firmalarca ekonomik bulunmadığından ya da sahipleri çıkaramadıklarından yapılamamaktadır. İlaç çeşidi yönünden en az olan ülkelerden biriyiz. Ortak Pazar ülkelerinde ilaç çeşidi 5.000-12.000 civarındadir. 
Sayın dinleyicilerim, milli ilaç sanayiimizin sorunlarına kısaca göz atmak isterim. Bu sorunları birkaç başlıkta toplamak mümkündür.

1. Yetkililerce sanayiimizi ilgilendiren hususlarda taraf olarak kabul edilmiyoruz. Yapılan kanun, kararname veya komisyonlarda resmi olmasa dahi müşahit olarak temsil edilmemizi veya çağrılmamızı talep ediyoruz. Teorik bilgilerle yapılacak hazırlıklara pratiği de katarak hem daha realist davranılmış, hem de sonradan uzun sürtüşmelere sebep olacak bazı hususların önlenmesi ile zamandan tasarruf edilmiş olur.

2. İlaç sanayiinde çalışacak veya kendi müteşebbis olacak yetişmiş eczacılara ihtiyaç var. Sevinerek görüyoruz ki Ankara Eczacılık Fakültesi bu hususta Yüksek lisans eğitimine ait program yapmıştır. $\mathrm{Bu}$, memleketimiz için çok sevindirici ve hayırlı bir husustur. $\mathrm{Bu}$ Yüksek Lisans programım hazırlayan yöneticilere takdirlerimi ve teşekkürlerimi arzediyorum.

3. 1262 sayılı Kanunun yeniden düzenlenen taslağ 1 hakkında görüşlerimiz nazara alınmamıştır. Sanayiimizi ilgilendiren ve çok uzun seneler yürürlükte kalacak bu kanunda bir takım yanlışlıklar görmekteyiz. Bu husustaki görüşlerimizi ayrı bir yazı ile S.S.Y.B.'na ve diğer ilgili yerlere bildirdik. Bu kanuna itirazlar1mız kendi menfaat açımızdan değildir. Ulusal Sanayiimizin sağlıklı gelişmesi ve yarının imalatçısı genç eczacılarımızın sıkıntı çekmelerini önlemeye yöneliktir.

4. İlaçlarımızı tanıtmada karşılaştığımız sıkıntıları; ilaç fiyatlarını tesbit eden kararname, ilaçlar için ruhsatname tarihinden itibaren üç sene ve imalatınım \% 5'i kadar numune dağıtılır kaydını getirmiştir.

1972 senesinde kabul edilen kararnameye göre o sene mevcut çok sayıda ilaç için numune dağıtılmayacak hale gelmişlerdir, yani bu seneden sonra mezun olmuş veya talebeliği devam eden doktor ve eczacılar için her ilaç yenidir. İlaçları tanımak ve tanıtmak mecburiyeti vardır, bu yanlış tatbikatın değişmesi hususunda ilgililerin ve sizlerin görüşlerinizi bekliyoruz.

5. İlaç fiyatlarını tesbit eden Fiyat Kararnamesi :

1972 senesinde kabul edilen kararname Sayın Mekin Tanker'in başkanlığını yaptığı bir komisyonun hazırladığı rapora istinat et- 
mektedir. $\mathrm{Bu}$ komisyon, raporunda birçok alternatif koymuş S.S.Y.B. bu alternatiflerin içinde en iyilerini bırakarak, bünyemize en uymayan alternatifleri kabul etmiş, ayrıca da bir sürü değişiklik yapmış olup, Komisyonun raporu tanınmaz hale gelmiştir.

Ayrıca uzun seneler kararname hükümleri tatbik edilmemiş, keyfi fiyat uygulamaları tatbik edilmiştir. Birkaç senedir kararname hükümleri tatbik edilmeye başlamış ancak bir maddesi yanlış anlaşılarak uygulanmaktadır; bu madde şöyledir, Bakanlığımızın fiyat endeksi ilanından sonra husule gelen sınai maliyetlerdeki çıkış ve inişler \% 20'yi bulursa fiyatlar değiştirilir. Bu madde endeks aralarında sık sik fiyat değişikliğini önleyecek istikrar unsuru olarak konmuştur, yalnız tatbikatta böyle olmamaktadır. Yeni endeks ilanında bu madde işletilmektedir. Yeni endeksle yeni fiyatlar ilan edildiği halde bu madde işletilince artık hükmü kalmamış olan eski endekse göre fiyatlandırma devam ettirilmekte, bu da hukuka aykırı düşmektedir.

Ayrıca enflasyonun değiştiği ve düşmeye devam edeceğinden şüphemiz olmadığ bu ortamda \% 20 rakamı çok büyüktür. Sınai maliyeti \% 19'u geçip \% 20'yi bulamamış bir ilacı düşünüyoruz. Karlılığ1 kararnameye göre \% 12,5 olan sanayicimiz için bu katlanılması çok güç bir durumdur.

$\mathrm{Bu}$ hususun acilen düzeltilmesi icap eder.

6. İlaç Ruhsatları :

Ankara Eczacılık Fakültesi Yüksek Lisans programı ile ilaç sanayiine yönelik ihtisas görmüş eczacı yetiştirmek üzere harekete geçmiştir. Burada yetişecek eczacı iki şekilde hareket edecektir. layacak,

1) İlaç sanayiinde herhangi bir ilaç firmasında çalışmaya baş-

2) Anayasamızda öngörüldüğü şekilde, serbest hayatı seçerek kendi firmasını kuracaktır.

İkinci şıkk1 seçen eczacımız imalathanesini şartnameye göre hazırlayıp imalathane müsaadesini aldıktan sonra ilaç imal etmeye başlamaması için bir sebep kalmamıştır. Önce kodeks kalemleri ve benzer ilaçları için ruhsat alıp işe başlaması sonra araştırmaya yönelmesi en tabii yoldur. Ancak tatbikat, aşağıda arzedeceğim sebeplerle, bu şekilde yürümemektedir. 
Bakanlığımızın ruhsat verme işlemi şöyledir;

Bakanlık bünyesinde, istişari mahiyette, bilimsel komisyon adı altında başvuruları incelemek ve sağlığa faydasız veya zararlı ilaç hüviyetindeki müracaatlara ruhsat vermemek, faydalı ilaçlara ruhsat vermektir.

Halbuki komisyonun çalışmaları böyle değildir. 1972 senesinden sonraki uygulama, "Benzeri yeteri kadar mevcut olduğundan yenisine ihtiyaç yoktur" diyerek ruhsat vermeme şeklinde olmuştur.

$\mathrm{Bu}$ sene ise bilimsel komisyon ruhsat alınmasını bir takım yeni şartlara bağlanmış ve kanun ve kararnamelerle verilmeyen bir hakkı kullanmaya başlamıştır.

1262 sayılı Kanunda ve yeni hazırlanan kanun taslağında dahi kodekste kayıtlı kalemlere ruhsat alma mecburiyeti olmadığ 1 halde, komisyon bu hakkı kullandırmamakta ve ruhsat alma mecburiyeti koymaktadir.

Kodeks'e kanunla kabul edilmiş ve bilimselliği tartışılmaz olan bazı çeşitler için bir takım bilgiler istenmektedir. Bu bilgilerin bazıları şöyledir.

Farmasötik şekil, Farmakolojik bilgi (in vitro ve in vivo deneysel farmakolojik bulgular) toksikoloji, biyoyararlılık bulguları ve literatür gibi adeta kodekse girmiş maddelerin çok açık yazılmış bilgilerin yeniden araştırması istenmekte ve bu bilgilerin toplanması halinde dahi 2 seneyi geçen bir zaman kaybolmaktadır. Bu bilgiler verilmedikçe ruhsat verilmemektedir.

Ayrica kodekste olmayıp da piyasada bulunan bir ilacin benzerine ruhsat verilmemekte, bu halde bazı firmalara imtiyaz tanınmış olmaktadır. Komisyon, Türkiye'de bulunmayan yeni ilaçlara ruhsat talebinde de bir takım bilgiler ve literatür istemektedir. $\mathrm{Bu}$ bilgileri istemekte haklıdır, ancak 3 gelişmiş ülkede piyasaya verilmiş olma kaydım koymaktadır. Bu durum ulusal sanayiimiz için çok büyük müşkülat yaratmaktadır.

$\mathrm{Bu}$ durumdan ya bu işlem kaynağında olan yabancı sermayeli ilaç firmaları faydalanmakta veya patent ve lisans alma mecburiyeti doğmaktadır. Her ikisi de döviz kaybı ve uzun vadede bağımlı olmak ve ulusal sanayiimizi patentle çalışmaya zorlamak demektir. 
Ayrıca aynı anda yeni bir ilaca müracaat eden birkaç firma varsa bunlardan birkaçının kırtasî eksikliği bile olsa ona ruhsat verilmesi geciktirilmekte ve yarışta baştan kaybetmektedir.

Bizim görüşümüz şudur, gelişmekte olan ülkeler yabancı sermayeye muhtaçtır. Döviz girdisi ve teknolojisi için ulusal sanayi yabancı sermayenin yaptığının benzerini yaparak ilerliyecektir. Bu yolu kapamak akılla kaim değildir.

Bilimsel komisyonun vazifesi dünyadaki yenilikleri takip etmek Üniversitelerimizle ve sanayiimizle ilişki kurarak yenilikleri zaman geçmeden tesbit etmek standardize edip en kısa zamanda kodeks ekleri çıkararak, memlekete ve ulusal sanayie yardımcı olmaktır. Ayrıca artık bilimselliğinden şüphesi olmadığ bir firmaya ruhsat verdiği zaman, diğer müracaatlara da zaman kaybetmeden ruhsat vermesi icap eder. Yeniden aynı bilgileri derletmek toplattırmak kirtasiyecilikten ileri gitmeyen bir hareket olduğu gibi, ulusal sanayiimizin gelişmesini sağlayacak en önemli yolu kapatmak olacaktır. Ayrıca aynı ilaçtan bir çok firma piyasaya çıkarabilirse bundan halkımız en büyük istifadeyi sağlar. Zira rekabet hem kaliteyi yükseltir, hem de fiatların ucuzlamasına sebep olur.

Komisyon öyle ruhsatnameler verdi ki, önce müracaat edenler ruhsat alamad1, sonra müracaat edenler ruhsat alarak haksız rekabete sebep oldu. Son zamanlarda bu misali açıkça gördük. 4-5 sene önce bir ilaca müracaat eden firmalar ruhsat alamayıp sonra müracaat eden bir firma ruhsat almış ve başka firmalara ruhsat verilmediği için tek olarak piyasaya çıkmıştır. Halbuki bu ilacın bilimselliği kabul edildiğine ve dünyada da en az 8-10 senelik ilaç olduğuna göre niçin bir firmaya veriliyor da diğerlerine beraberce verilmiyor. Eğer müracaatçılara aynı anda ruhsat verilseydi belki de halkımız bu ilacı daha ucuza alacaktı.

Ayrica 8-10 senedir dünyada kullanılan ve 4-5 sene önce müraacatı yapılan bu ilaçtan halkımız neden bukadar geç istifade etmiştir diye sorumuzun cevabinı almak zor oluyor.

$\mathrm{Bu}$ sebeple;

Bilimselliğine inanılan ilaçlara kırtasi külfet yükleme lüzumu kalmadan ve benzeri vardır yenisine lüzum yoktur ibaresini kullanmadan yeni teşebbüs açılması ve çalışına özgürlügünün sağlanacağ 1 ve tekelciliğe ve imtiyaz sağlayıcı hallere müsaade edilmeyecek bir şekilde hemen ruhsat verilmesi temin edilmelidir. 52 
- Kodekste kayıtlı kalemlere ruhsat istenmemeli veya imalini güçleştirici engeller çıkartılmamalı.

- Ruhsat müracaatları azami 6 ay içinde neticelendirilmeli.

- Bilimsel komisyona sanayiden müşahit alınmalı.

- Bilimsel komisyon broşürü değiştirilmeli.

- Bilimsel komisyon ruhsat verme işleminin ilerisine geçecek, yurttaaki ve dişardaki gelişmeleri takip edip bunları en k1sa zamanda ulusal sanayimizin istifadesine sunmalıdır. Bu hususlarda ruhsat verme tahdidi kaldırılmalıdır. Zira;

- Yabancı sermayeye ve lisansa ödenen dövizlere yazık olacaktır.

Onlardan istifade yolları kapatılmamalı ve bu yolları açmak için icap eden kolaylık gösterilmelidir.

- lisans öğrenimi verilip çalışma hayatını seçen müteşebbisin yolu ruhsat almakla kapatılmamalıdir.

Ruhsatlarla ve sorunlarımızla ilgili Cemiyetimizin görüşleri ayrı yazılarla ilgililere iletilmiştir.

Sorunlarımızı bu dar zamana sığdırmak mümkün değildir. Sizleri yormamak için, sözlerimi bitirirken beni sabırla dinlediğiniz için teşekkürlerimi arzederim. 
Doç. Dr. Eriş Asil'in Kapanış Konuşması

Sayın konuklarımız,

Atatürk'ün Doğumunun 100. ve Ankara Üniversitesi Eczacılık Fakültesi'nin 20. Öğretim yılını kutlama günlerinin sonuna gelmiş bulunuyoruz.

Bu iki olayı beraber kutladığımız üç gün süresince sizlerle olmanın mutluluk ve sevincini yaşadık. Toplantılara katılan Üniver sitemizin tüm Öğretim Üyelerine, ilgili Bakanlık mensuplarına, meslektaşlarımıza, meslek kuruluşları ve ilaç sanayiimizin seçkin temsilcilerine ve sevgili öğrencilerimize teşekkür ediyoruz.

Programımız hepimizin izlediği gibi dört bölümden oluşuyordu. İlk bölümde Atatürk Yılı konuşmaları yer aldı. İkinci bölümde Fakültemizin 20 y1lı anlatıldı. Yüksek lisans programımızı ayrıntılı olarak tanıtmaya çalıştık. Üçüncü bölüm tümüyle ilaç sanayiine ayrılmıştı. Gerek konuşmalar, gerekse filmlerle ilaç sanayiimizi daha yakından tanıdık. Sanayi - Üniversite işbirliğinin gereğine olan inancımız daha da pekişti. Bu işbirliğinin gerçekleşeceğini ümit ediyoruz. Programımızın dördüncü ve son bölümü ise sosyal içerikli etkinliklere ayrılmıştı. Bunlar arasında toplu sanat gösterileri ve tiyatro, oyuncusundan yöneticisine ve müzisyenine kadar tümüyle Fakültemiz öğretim elemanları ve öğrencileri tarafından gerçekleştirildi.

Programımızı planlarken üç gün boyunca Atatürk ilkeleri çerçevesinde ülkemiz eczacılığına 1 şı tutmayı, beraber düşünmeyi, sorunlara çözüm aramayı ve bütün bu yoğun çalışmalarımız içinde sizlere hoşça vakit geçirtebilmeyi amaçladık. Amacımıza ulaşabildiysek yorgunluklarımızı unutacağız.

Atatürk'ün Doğumu'nun 100. ve Ankara Üniversitesi Eczacilık Fakültesinin 20. Öğretim Yılını Kutlama günlerini kapatırken hepinizi sayg1 ve sevgiyle selâmlıyoruz. Katılan ve katkıda bulunan herkese ve Kuruluşlara teşekkürlerimizi yineliyoruz. Hoşçakalın..., 
Ankara Eczacı Odası Başkanı Ecz. Nermil Usal'ın konuşması Ankara Eczacı Odası Bülteni, 3 (5) , 15 -17 (1981) de, İlaç Endüstrisi İşverenleri Sendikası adına konuşan Ecz. Nurettin Turan'ın konuşması, İlaç, Türkiye İlaç Endüstrisi İşverenleri Sendikası Yayını, Tüm Matbaacılık, 1981'de ayrıntılı olarak yayınlandığı için yeniden yayınlanmamıştır. Ayrıca Doç. Dr. Eriş Asil'in "Atatürk'ün sağlık yaşamı" konulu konuşması yeni belgelerinde eklenmesiyle ileride ayrıca yayınlanacağı için dergiye aknamamıştır. 
B İ L I M S E L M A KA L E L E R 